\title{
Biventricular assist device-induced recovery from acute heart failure in peripartum cardiomyopathy on cardiac magnetic resonance imaging
}

\author{
Joanna Petryka-Mazurkiewicz ${ }^{1,2^{*}}$, Karolina Kryczka1*, Miłosz Marona ${ }^{3}$, Jarosław Kuriata4, Ewa Sitkowska-Rysiak ${ }^{5}$, \\ Anna Konopka ${ }^{3}$, Magdalena Marczak²,6, Piotr Kołsut ${ }^{4}$, Mariusz Kuśmierczyk ${ }^{4}$, Marcin Demkow', Zofia Dzielińska ${ }^{1}$ \\ 1 Department of Coronary and Structural Heart Diseases, National Institute of Cardiology, Warsaw, Poland \\ 2 Magnetic Resonance Imaging Unit, National Institute of Cardiology, Warsaw, Poland \\ 3 Department of Intensive Cardiac Therapy, National Institute of Cardiology, Warsaw, Poland \\ 4 Department of Cardiac Surgery and Transplantology, National Institute of Cardiology, Warsaw, Poland \\ 5 Department of Anesthesiology, National Institute of Cardiology, Warsaw, Poland \\ 6 Department of Radiology, National Institute of Cardiology, Warsaw, Poland
}

\section{Correspondence to:}

Joanna Petryka-Mazurkiewicz, MD, PhD, Department of Coronary and Structural Heart Diseases, National Institute of Cardiology, ul. Alpejska 42, 04-628 Warszawa, Poland, phone: +48223434342 ,

email: jpetryka@ikard.pl Received: July $16,2020$.

Revision accepted:

August 18, 2020

Published online:

August 26, 2020

Kardiol Pol. 2020;

78 (12): 1284-1285

doi:10.33963/KP.15586

Copyright by the Author(s), 2020

*JP-M and KK contributed equally to this work.
A 26-year-old woman presented with acute-onset heart failure 3 days after giving natural birth to a healthy infant (gravida 1, para 1). Echocardiography revealed an enlarged left ventricular end-diastolic diameter of $68 \mathrm{~mm}$, decreased left ventricular ejection fraction (LVEF) of $17 \%$, and moderate mitral regurgitation. The patient was diagnosed with peripartum cardiomyopathy (PPCM) and referred for cardiac magnetic resonance imaging (MRI), which confirmed a severely dilated left ventricle (LV) with impaired ejection fraction of $19 \%$ (Supplementary material, Videos S1 and S2). Right ventricular (RV) volumes and function were normal with RVEF of $52 \%$. On T2-weighted imaging, no rise in the T2 signal was noted. Importantly, T1-mapping revealed a significant increase in the T1 signal in the interventricular septum (T1 = $1352 \mathrm{~ms}$; mean [SD] reference range, 940.7 [49.2] ms) despite lack of late gadolinium enhancement (FIGURE 1). Extracellular volume (ECV) was significantly elevated at $36 \%$. Laboratory tests showed the elevated levels of N-terminal fragment of the prohormone brain natriuretic peptide and high-sensitivity troponin T: $10275 \mathrm{pg} / \mathrm{ml}$ (reference range $<125 \mathrm{pg} / \mathrm{ml}$ ) and $52.78 \mathrm{ng} / \mathrm{l}$ (reference range $<14 \mathrm{ng} / \mathrm{l})$, respectively.

In the following days, the patient developed cardiogenic shock and required arteriovenous extracorporeal membrane oxygenation. On day 42 after delivery, the treatment was converted into the use of the first Polish pulsatile-flow mechanical circulatory support system - POLCAS. First, the LV was supported by the cannulation from the $\mathrm{LV}$ to the aorta. Two weeks later, due to RV function deterioration, the RV POLCAS system was implanted. The clinical course was complicated by device-related thrombus formation despite anticoagulation and, therefore, the device was explanted on day 88 after delivery. At that stage, LVEF ranged between $25 \%$ and $30 \%$ on echocardiography. The subsequent cardiac MRI scan revealed a significant improvement in the contractility of the basal and mid segments of the LV, while apical akinesia and tethering were observed in the region of the scar after removing the $\mathrm{LV}$ assist device (Supplementary material, Videos S3 and S4). The LV and $\mathrm{RV}$ volumes were normal with LVEF of $35 \%$ and RVEF of $46 \%$. Importantly, on T1 mapping, the T1 signal dropped to $1104 \mathrm{~ms}$ (FIGURE1). The patient's status gradually improved and the woman was discharged home with New York Heart Association class II. At 6-month follow-up, the level of $\mathrm{N}$-terminal fragment of the prohormone brain natriuretic peptide decreased to $1019 \mathrm{pg} / \mathrm{ml}$, and the high-sensitivity troponin $\mathrm{T}$ level was within reference range.

Peripartum cardiomyopathy is a rare and potentially life-threatening condition. Several studies demonstrated that the presence of LVEF $<30 \%$ and left ventricular end-diastolic 


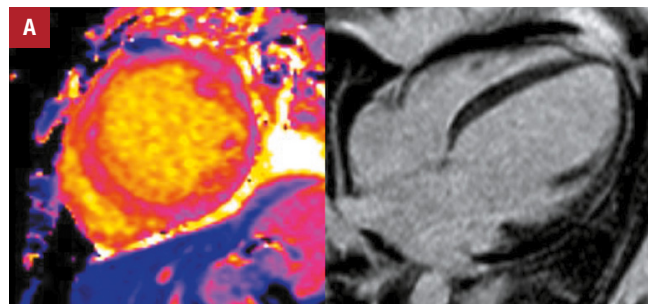

T1 mapping

LGE

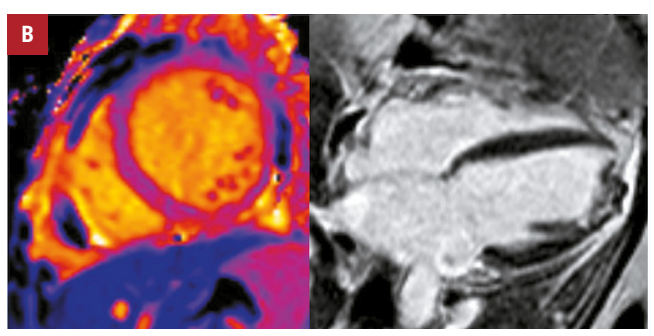

T1 mapping

LGE

FIGURE 1 Cardiac magnetic resonance imaging at baseline (A) and following the treatment with a biventricular assist device (B) in a patient with peripartum cardiomyopathy Abbreviations: LGE, late gadolinium enhancement

diameter $>60 \mathrm{~mm}$ is associated with unfavorable outcomes. ${ }^{1}$ Although echocardiography is the most commonly available imaging modality, cardiac MRI with native T1 mapping offers a unique, noninvasive way to evaluate myocardial fibrosis and measure ECV. Cardiac MRI plays a crucial role in the management of various types of cardiomyopathy., Increased ECV, with a cutoff value of $32.5 \%$, has been associated with worse outcomes in PPCM. ${ }^{4}$ The case of our patient indicates that prompt heart failure treatment with bromocriptine and assist devices, if needed, may lead to favorable outcomes. As the signs of fibrosis can be detected by cardiac MRI at an early disease stage, we suggest using cardiac MRI with T1 and T2 mapping in every patient with PPCM on admission to guide the management and predict the outcome. Furthermore, cardiac MRI can help to accurately assess apical akinesia and scarring resulting from $\mathrm{LV}$ assist device implantation.

\section{SUPPLEMENTARY MATERIAL}

Supplementary material is available at www.mp.pl/kardiologiapolska.

\section{ARTICLE INFORMATION}

\section{CONFLICT OF INTEREST None declared.}

OPEN ACCESS This is an Open Access article distributed under the terms of the Creative Commons Attribution-NonCommercial-NoDerivatives $4.0 \mathrm{In}$ ternational License (CC BY-NC-ND 4.0), allowing third parties to download articles and share them with others, provided the original work is properly cited, not changed in any way, distributed under the same license, and used for noncommercial purposes only. For commercial use, please contact the journal office at kardiologiapolska@ptkardio.pl.

HOW TO CITE Petryka-Mazurkiewicz J, Kryczka K, Marona M, et al. Biventricular assist device-induced recovery from acute heart failure in peripartum cardiomyopathy on cardiac magnetic resonance imaging. Kardiol Pol. 2020; 78: 1284-1285. doi:10.33963/KP.15586

\section{REFERENCES}

1 Bauersachs J, Arrigo M, Hilfiker-Kleiner D, et al. Current management of patients with severe acute peripartum cardiomyopathy: practical guidance from the Heart Failure Association of the European Society of Cardiology Study Group on peripartum cardiomyopathy. Eur J Heart Fail. 2016; 18: 1096-1105.

2 Dąbrowski M, Kukuła K, Kłopotowski M, et al. Reduction of left ventricular mass, left atrial size, and N-terminal pro-B-type natriuretic peptide level following alcohol septal ablation in patients with hypertrophic obstructive cardiomyopathy. Kardiol Pol. 2019; 77: 181-189.

3 Gawor M, Mazurkiewicz Ł, Milanowska B, Grzybowski J. Recovery from heart failure in a patient with cardiac amyloidosis treated with autologous stem cell transplantation. Kardiol Pol. 2017; 75: 83.

4 Liang YD, Xu YW, Li WH, et al. Left ventricular function recovery in peripartum cardiomyopathy: a cardiovascular magnetic resonance study by myocardial $\mathrm{T} 1$ and T2 mapping. J Cardiovasc Magn Reson. 2020; 22: 2. 